\title{
QUEEN'S
UNIVERSITY
BELFAST
}

\section{How to interpret mast cell tests}

Waterfield, T. (2016). How to interpret mast cell tests. Archives of Disease in Childhood: Education and Practice Edition. https://doi.org/10.1136/archdischild-2015-309887

Published in:

Archives of Disease in Childhood: Education and Practice Edition

\section{Document Version:}

Peer reviewed version

Queen's University Belfast - Research Portal:

Link to publication record in Queen's University Belfast Research Portal

\section{Publisher rights}

Copyright 2016 BMJ. This work is made available online in accordance with the publisher's policies. Please refer to any applicable terms of use of the publisher.

\section{General rights}

Copyright for the publications made accessible via the Queen's University Belfast Research Portal is retained by the author(s) and / or other copyright owners and it is a condition of accessing these publications that users recognise and abide by the legal requirements associated with these rights.

Take down policy

The Research Portal is Queen's institutional repository that provides access to Queen's research output. Every effort has been made to ensure that content in the Research Portal does not infringe any person's rights, or applicable UK laws. If you discover content in the Research Portal that you believe breaches copyright or violates any law, please contact openaccess@qub.ac.uk. 


\section{"How To Interpret Mast Cell Tests"}

Corresponding Author: Dr Thomas Waterfield

Address: Royal Belfast Hospital for Sick Children 180-184 Falls Rd, Belfast, County Antrim BT12 6BE.

Email: Thomas.waterfield@gmail.com

Telephone: 02890240503

Fax: Not Available

Co-Authors

$2^{\text {st }}$ Author: Dr Emma Dyer

Royal Free Hospital

London

UK

$3^{\text {rd }}$ Author: Dr Kathryn Wilson

Royal Belfast Hospital For Sick Children

Belfast

UK

$4^{\text {th }}$ Author: Dr Robert J Boyle

Imperial College London

London

UK

Keywords: General Paediatrics, Allergy, Anaphylaxis, Tryptase, mastocytosis 
Word count: 2609

\section{Abstract:}

Anaphylaxis is a systemic life-threatening allergic reaction, which is typically caused by an IgE mediated response to allergen with resultant degranulation of mast cells. This degranulation results in a range of symptoms including respiratory distress secondary to bronchospasm and/or haemodynamic collapse secondary to vasodilatation, capillary leak, and direct cardiac effects of mast cell mediators. The diagnosis of anaphylaxis is made clinically (table 1) but in some instances the diagnosis may be difficult e.g. post-mortem, out of hospital collapse, under anaesthetic or in response to medications. In these ambiguous cases a diagnostic test would be useful in helping to confirm or refute the diagnosis.

In addition to having a specific and sensitive test for anaphylaxis it would also be very useful to have a test that could help to predict the risk of future anaphylaxis in allergic children. Such a test would help to inform clinicians and parents as to the risk and benefits of carrying an adrenaline auto-injector.

Mast cell tryptase (tryptase) is an enzyme produced almost exclusively by mast cells that is easy to test and widely available. The research into the role of this enzyme as a marker of anaphylaxis, and as a predictor of future anaphylaxis risk is discussed below. In addition to anaphylaxis mast cells are implicated in a number of haematological disorders including mastocytosis and the role of tryptase in the diagnosis of these conditions in also discussed below. 


\section{How to use "Mast Cell Tryptase"}

\section{Introduction:}

Anaphylaxis is a systemic life-threatening allergic reaction, which is typically caused by an IgE mediated response to allergen with resultant degranulation of mast cells. This degranulation results in a range of symptoms including respiratory distress secondary to bronchospasm and/or haemodynamic collapse secondary to vasodilatation, capillary leak, and direct cardiac effects of mast cell mediators. The diagnosis of anaphylaxis is made clinically (table 1) but in some instances the diagnosis may be difficult e.g. post-mortem, out of hospital collapse, under anaesthetic or in response to medications. In these ambiguous cases a diagnostic test would be useful in helping to confirm or refute the diagnosis.

Table 1: Diagnosing Anaphylaxis (1)

\begin{tabular}{lll} 
Mucosal Symptoms & Respiratory Symptoms & Cardiovascular Symptoms \\
\hline Hives/Itchy Rash & Difficulty Breathing & Hypotension \\
Swelling of lips/tongue & Collapse \\
Swelling of back of throat & \\
Vomiting/Stomach cramps & \\
To diagnose anaphylaxis symptoms from two columns need to be present with minutes to hours of allergen exposure
\end{tabular}

In addition to having a specific and sensitive test for anaphylaxis it would also be very useful to have a test that could help to predict the risk of future anaphylaxis in allergic children. Such a test would help to inform clinicians and parents as to the risk and benefits of carrying an adrenaline auto-injector. 
Mast cell tryptase (tryptase) is an enzyme produced almost exclusively by mast cells that is easy to test and widely available. The research into the role of this enzyme as a marker of anaphylaxis, and as a predictor of future anaphylaxis risk is discussed below. In addition to anaphylaxis mast cells are implicated in a number of haematological disorders including mastocytosis and the role of tryptase in the diagnosis of these conditions in also discussed below.

This paper is to the best of our knowledge the first to explore the role of tryptase exclusively in paediatrics.

\section{Physiological Background - The Mast Cell}

Mast cells are a part of the innate immune system and they develop from the CD34+ multipotential bone marrow cells. The developing mast cells are initially found circulating in peripheral blood but later settle in organs that have direct interaction with the environment such as gut, respiratory tract and skin. These locations suit the mast cell's role as a member of innate immune system responsible for pathogen sensing and mediating inflammatory responses.

Mast cells degranulate in response to a range of stimuli including trauma, high temperatures and bound antibody. It is this later response that is responsible for the classical type 1 hypersensitivity reaction. In type 1 hypersensitivity reactions the body produces IgE antibodies on first exposure to a harmless environmental protein e.g. peanut. On subsequent exposure the IgE binds the antigen and then activates mast cells. The mast cells then release the contents of their secretory granules (cytokines, Histamine, tryptase, chymase etc) resulting in a type 1-hypersensitivity reaction. (Figure 1) 


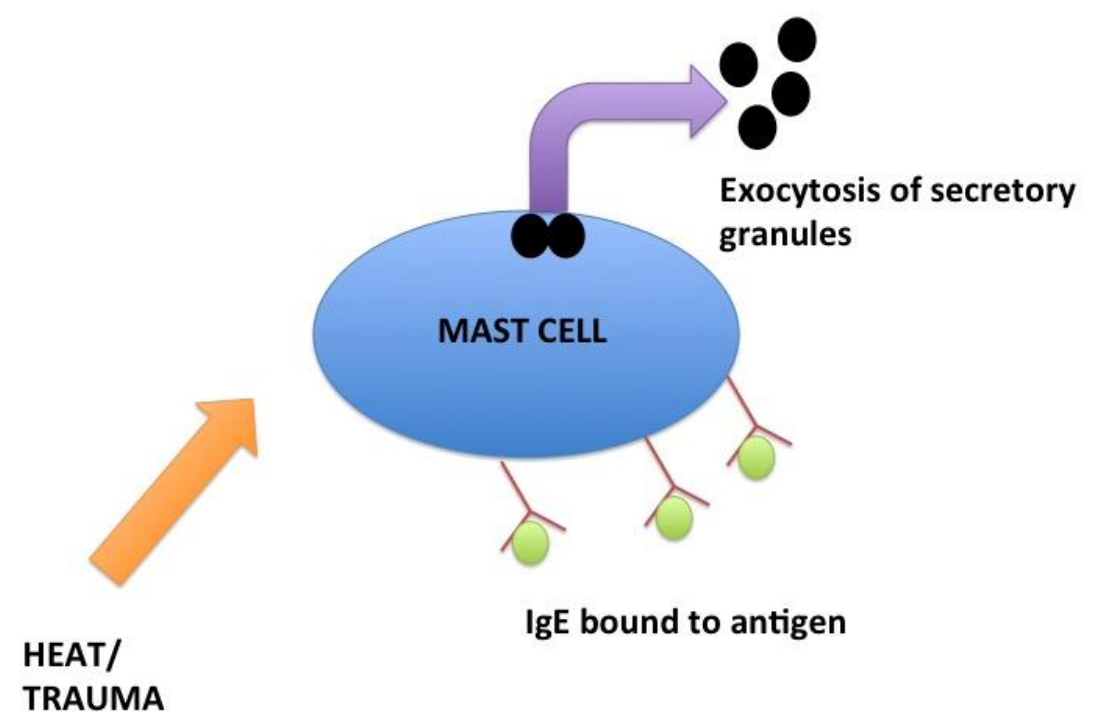

\section{Physiological Background - Mast Cell Tryptase (Tryptase)}

The tryptase enzyme (also known as mast cell, or beta-tryptase) is highly specific to the mast cell. The role of tryptase in the immune response and anaphylaxis is unclear. Tryptase can degrade mediators of bronchodilation and has effects on nitric oxide mediated vasodilatation possibly contributing to bronchospasm and hypotension respectively (2). Following an anaphylactic reaction tryptase levels rise with peak secretion from the mast cell at 15 minutes to 2 hours (2). The peak level in the blood is usually measurable at 1-6 hours after the onset of anaphylaxis with tryptase having a half-life of around 2 hours and the levels returning to normal at around 24 hours (3). Based on these timings it is recommended that when used for the diagnosis of anaphylaxis at least three samples are taken (2). The first is taken at the onset of the reaction, another at 1 hour and the third at 24 hours. An additional sample may need to be taken at 1 week after the reaction to establish a true baseline tryptase level(4). Whilst in the majority of cases a raised tryptase level will represent anaphylaxis it is worth noting that there are other causes of an elevated tryptase (2) (see table 2) 


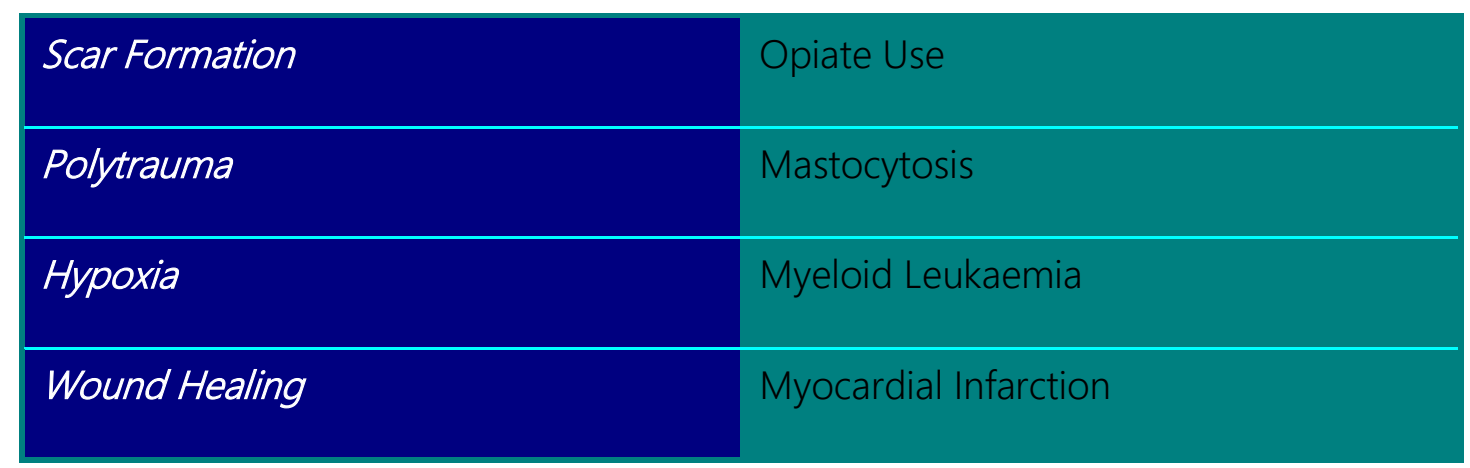

Ref: Michalska-Krzanowska G et 2012 (2)

\section{Technological Background}

The only commercially available method for measuring tryptase levels is the sandwich enzyme-linked immunosorbent assay (ELISA) known as (ImmunoCAP Tryptase) produced by (ThermoFisher Scientific Diagnostics, Phadia, Sweden). The Sandwhich ELISA is more sensitive than the standard ELISA technique and samples do not requiring purification prior to testing. The ImmunoCAP Tryptase involves the following steps(5).

1. The anti-tryptase is added to the patients serum and binds to the trypase

2. The sample is washed and enzyme-labeled antiboides against tryptase are added creating a complex

3. The complex is incubated with a developing agent

4. At the end of the reaction the fluorescence is measured and is directly proportional to the amount of tryptase in the sample.

Blood samples for tryptase analysis can be collected in a clotted sample and sent to the laboratory at room temperature (6). The serum should be separated from blood and analysed (6). The tryptase enzyme is very stable and can be stored for 2 days at room temperature, for 5 days at $2-8 \mathrm{C}$ and for longer periods if stored at $-20 \mathrm{C}$ to $-70 \mathrm{C}(6)$.

\section{Normal Ranges:}


Tryptase levels should ideally be viewed as a continuum with no clear normal range. From the existing data however, the median tryptase level in non-atopic children aged 6 months to 18 years is $3.5 \mathrm{ug} / \mathrm{l}$ (assessed on a total of 410 healthy and non-atopic children) (7-9). This level is similar to that seen in healthy adults $(3.8 \mathrm{ug} / \mathrm{l})$ with $95 \%$ of healthy adults having a tryptase level less than $11.4 \mathrm{ug} / \mathrm{I}(6)$.

Children under 6 months show higher levels of tryptase with a median level of $6.1 \mathrm{y} / \mathrm{l}(8)$. This level then gradually reduces (8).

\section{Indications and limitations:}

In a child presenting shocked in whom anaphylaxis is a possibility can tryptase measurements be used to confirm or refute anaphylaxis as a cause?

Anaphylaxis is primarily a clinical diagnosis and the role of tryptase is as a tool to help confirm or refute the diagnosis when there is an element of clinical uncertainty. There have been a number of suggested approaches for how one might interpret tryptase levels to diagnose anaphylaxis. The first is to use the $11.4 \mathrm{ug} / \mathrm{l}$ as an upper limit and to confirm anaphylaxis in anyone with a level above that(10). This value has been chosen as it presents the upper limit seen in a population of healthy adults. The other is to use a measure of 1.2 times the baseline level $+2 u g / l$ as a cut off (10)

Until recently there was very little data on how effective either of these approaches are in diagnosing anaphylaxis in children with most available data looking at adult populations with anaphylaxis. A recently published Canadian study looked at 203 children with anaphylaxis measured the tryptase levels at 30 minutes and 2 hours(10). Overall only $19.2 \%$ of the children 
in that study had a maximum tryptase level greater than $11.4 \mathrm{ug} / \mathrm{I}(10)$. Furthermore even in the group with the severest reactions only $71 \%$ of children had a tryptase level above 11.4ug/l(10). Of the 203 children; 68 had a baseline tryptase level measured. Of those with anaphylaxis $60.3 \%$ had a maximal tryptase level of greater than 1.2 times their baseline + 2ug/I(10). This study is the largest paediatric anaphylaxis study exploring the role of tryptase as a diagnostic test for anaphylaxis and it demonstrates that a tryptase level is not a sensitive test for anaphylaxis (10).

These results reflect data from adult studies with a similarly designed adult study of 102 patients with clinically confirmed anaphylaxis finding that tryptase levels were not elevated beyond baseline (baseline measure at 1 week after the event) in $36.3 \%$ of patients (4). The authors also went on to highlight that in their study food allergy induced anaphylaxis was less likely to result in an elevated tryptase level when compared to venom or drug induced anaphylaxis. This has been attributed to food allergies leading to more localised mast cell degranulation than with drugs or venom; with the result of less tryptase entering the circulation despite being released locally (4). This finding is not consistent within the literature and more research is required to understand how food/venom and drug induced anaphylaxis affect tryptase levels(11). The possibility that tryptase levels are less reliable for determining food induced anaphylaxis is significant for the paediatric population because the majority of paediatric anaphylaxis is secondary to food (12).

For the general pediatrician measuring tryptase levels in cases of suspected anaphylaxis is of limited value. Tryptase levels are not sensitive for anaphylaxis and although specific there remains uncertainty as to how to interpret levels and at what level anaphylaxis can be assumed to have occurred (10). Tryptase level measuring is unlikely to be helpful in cases of clear-cut anaphylaxis, but where the cause for systemic symptoms is not clear eg unexplained hypotension during anaesthesia - finding a raised mast cell tryptase can be useful for 
confirming that the episode was indeed anaphylaxis.

In a child who has died of suspected anaphylaxis can tryptase levels be measured postmortem to confirm anaphylaxis as a cause of death?

Diagnosing a case of fatal anaphylaxis post mortem can be difficult. Thus, having blood markers to help confirm this diagnosis is in theory very helpful. Tryptase levels have been shown to be raised in cases of anaphylactic deaths and it had been suggested that tryptase levels post mortem can be used to confirm anaphylaxis (13). It has also been shown however, that a modest rise in tryptase levels is common post mortem with $34.5 \%$ of non-anaphylactic post mortem cases demonstrating a tryptase level of $>11.4 \mu \mathrm{g} / \mathrm{L}(14)$.

There are currently several controversies related to the use of measuring tryptase levels in post-mortem and these include:

1) There is no consensus at to a cut off level at which anaphylaxis can be confirmed as occurring with authors suggesting a range of $>45 \mathrm{ug} / \mathrm{l}$ to $>110 \mathrm{ug} / \mathrm{l}(14,15)$.

2) The mode of death can significantly affect the tryptase level and in particular death by asphyxia can cause a significant tryptase rise(15).

3) There is no consensus on the best site for sampling with differences in tryptase levels observed between samples taken from femoral vessels and from the heart $(15,16)$

4) There is no consensus as to the best timing of sampling (14).

5) The existing data focuses on adults and must be interpreted cautiously in regards to anaphylaxis in children 
From the evidence available tryptase levels can be useful post mortem but care needs to be taken to ensure that the time of sampling, site of sampling and nature of death are recorded. A very high tryptase level $>110 \mathrm{ug} / \mathrm{l}$ is very suggestive of anaphylaxis having occurred but lower levels cannot rule out or rule in anaphylaxis. More data is required before tryptase levels can be interpreted reliably in children post mortem.

In a child with known allergy can a baseline tryptase level be used to predict the likelihood of future anaphylaxis?

At present there is no test that can accurately predict the likelihood of future anaphylaxis (10). As we begin to view serum tryptase level as a continuum rather than a positive/negative test it opens up the possibility of using baseline serum levels to predict anaphylaxis risk.

There appears to be a trend in the literature towards reporting that children with higher baseline tryptase levels have increased anaphylaxis risk. The risk however is hard to calculate because the tryptase level and relative risk varies depending upon the allergen. The overall trend is however that the higher the baseline level of tryptase the greater the future anaphylaxis risk. The table below (Table 3 ) is an attempt to combine the existing data on baseline tryptase levels and future risk of anaphylaxis in allergic individuals $(2,17,18)$. There is very little data overall and there is no paediatric data exploring the risk for individual foods (just data on "food allergies"). 


\begin{tabular}{|c|c|c|c|c|c|c|}
\hline Allergen & \multicolumn{3}{|c|}{$\begin{array}{l}\text { Moderate Risk (>50\% Risk of } \\
\text { Anaphylaxis) }\end{array}$} & \multicolumn{3}{|c|}{$\begin{array}{l}\text { High Risk (>75\% Risk of } \\
\text { Anaphylaxis) }\end{array}$} \\
\hline Insect Venom & $\begin{array}{l}\text { Baseline } \\
>4.8 \mathrm{ug} / \mathrm{l}\end{array}$ & Tryptase & Level & $\begin{array}{l}\text { Baseline } \\
>8 \text { ug/l }\end{array}$ & Tryptase & Level \\
\hline Food Allergies & $\begin{array}{l}\text { Baseline } \\
>5.7 \mathrm{ug} / \mathrm{l}\end{array}$ & Tryptase & Level & $\begin{array}{l}\text { Baseline } \\
>14.5 \mathrm{ug} / \mathrm{l}\end{array}$ & Tryptase & Level \\
\hline
\end{tabular}

Table 3 - Predicting future anaphylaxis in allergic children based on baseline tryptase levels $(17,18)$

In a child with suspected mastocytotis can a tryptase level be used to confirm or rule out the diagnosis?

Mastocytosis is the haemotological disorder of clonal proliferation of abnormal mast cells It can have both systemic and cutaneous features such as flushing, abdominal pain, diarrhoea, pruritis, musculoskeletal pain, cutaneous lesions, hypotension and syncope.

Mastocytosis is usually spontaneous rather than inherited and in children it tends to manifest with cutaneous lesions, and resolve spontaneously by adulthood. Raised serum tryptase levels of $>20 \mathrm{ug} / \mathrm{L}$ are currently a minor diagnostic criterion is (Table4). Using the WHO criteria a patient requires either one major and 1 minor criterion or 3 minor criteria before a diagnosis of mastocytosis can be made (19). Therefor tryptase measurements alone are not sufficient to confirm or refute a diagnosis of suspected mastocytosis. 


\begin{tabular}{|ll|}
\hline Multifocal, dense aggregates of mast cells & In biopsy section, more than $25 \%$ of the \\
(15 or more) detected in sections of bone & masts cells in the infiltrate have atypical \\
marrow and confirmed by tryptase & morphology, or, of all the mast cells in the \\
immunohistochemistry or other special & aspirate smear, more than $25 \%$ are \\
stains & immature or atypical \\
& Mast cells co-express CD117 with CD2 \\
& and/or CD25 \\
& Detection of KIT point mutation at codon \\
& 816 in bone marrow, blood, or other \\
& extracutaneous organs \\
& Serum total tryptase persistently >20 ug/l \\
(not a valid criteria in cases of systemic \\
mastocytosis with associated clonal \\
hematologic non-mast-cell lineage disease)
\end{tabular}

Table 4: WHO criteria for systemic mastocytosis (19)

In a child with suspected or confirmed leukaemia can a tryptase level be used as a reliable tumour marker?

Currently tryptase measurements have no role in paediatric oncology except in research settings. There is very little data on the usefulness of tryptase as a tumour marker. One study of 914 adult and paediatric patients with haematological conditions (including mastocytosis) found that no patients with lymphoid leukaemias had an elevated tryptase level whereas $34 \%$ of patients with acute myeloid leukaemia (AML) did demonstrate an elevated tryptase level (>15ug/l) (20). It is worth noting however that none of the 317 cases of AML where in children under the age of $16(20)$.

In summary tryptase currently has no role in the diagnosis or management of paediatric haematological malignancies. 
Topics for further research:

1) There needs to be more research to determine in the paediatric population the tryptase level at which anaphylaxis can be assumed to have occurred.

2) More research is required to determine how best to measure tryptase levels post mortem in children and to determine an acceptable level at which anaphylaxis can be assumed to have occurred

3) More research is required to understand how to stratify risk of anaphylaxis in children with food allergies

\section{Clinical bottom line}

- Anaphylaxis is a clinical diagnosis

- When there is clinical uncertainty whether anaphylaxis has occurred tryptase measurements may be useful. Low levels do not rule out anaphylaxis (especially to food) but a high level is very suggestive of anaphylaxis.

- Mastocytosis cannot always be diagnosed or ruled out using a tryptase level

- A high baseline tryptase level may indicate a higher risk of future anaphylaxis

- Tryptase levels are difficult to interpret post mortem but a very high level $>110 \mathrm{ug} / \mathrm{l}$ is highly suggestive of anaphylaxis occurring prior to death

Appendix - search strategy: Search strategy and selection criteria

Information was obtained from Medline and PubMed searches for years between 1960 and 2015. Using the MESH search terms "Tryptase, allergy, allergic reaction, anaphylaxis, mastocytosis, leukaemia, malignancy, AML, acute myeloid leukaemia", original articles in English relating to tryptase were retrieved and their references searched for relevant clinical studies. 
1) Mast cells are predominantly found in the following tissues? (Select all that are correct)
a. Gut
b. Brain
c. Skin
d. Respiratory tract

Answer: A,C,D

2) In cases of suspected anaphylaxis tryptase levels should be recorded at the following times?
a. As soon as possible, 1 hour and 24 hours
b. 1 hour and 24 hours
c. 24 hours only
d. At 1 hour only

Answer: A

3) Tryptase levels are measured in a child with suspected anaphylaxis (but with ongoing diagnostic uncertainty). At which level can we confirm anaphylaxis?
a. 5ug/l
b. $1.2 x$ baseline
c. $1.2 \mathrm{x}$ baseline $+2 \mathrm{ug} / \mathrm{l}$
d. Baseline + 2ug/l

Answer C 
4) In which type of malignancy is tryptase a useful tumour marker?
a. ALL
b. AML
c. Nephroblastoma
d. None

Answer D

5) Which of the following are minor diagnostic features of mastocytosis?
a. Mast cells co-express CD117 with CD2 and/or CD25
b. Detection of KIT point mutation at codon 816 in bone marrow, blood, or other extracutaneous organs
c. Serum total tryptase persistently $>20 \mathrm{ug} / \mathrm{l}$
d. All of the above

Answer D

$\underline{\text { References }}$

1. National Institutes of Health. Guidelines for the Diagnosis and Management of Food Allergy in the United States Summary for Patients, Families, and Caregivers. USA: 2011. p. 25-8.

2. Michalska-Krzanowska G. Tryptase in Diagnosing Adverse Suspected Anaphylactic Reaction. Advances in Clinical and Experimental Medicine. 2012;21(3):403-8.

3. Schwartz LB, Yunginger JW, Miller J, Bokhari R, Dull D. TIME COURSE OF APPEARANCE AND DISAPPEARANCE OF HUMAN MAST-CELL TRYPTASE IN THE CIRCULATION AFTER ANAPHYLAXIS. Journal of Clinical Investigation. 1989;83(5):1551-5.

4. Sala-Cunill A, Cardona V, Labrador-Horrillo M, Luengo O, Esteso O, Garriga T, et al. Usefulness and Limitations of Sequential Serum Tryptase for the Diagnosis of Anaphylaxis in 102 Patients. International Archives of Allergy and Immunology. 2013;160(2):192-9.

5. Schwartz LB, Bradford TR, Rouse C, Irani AM, Rasp G, Vanderzwan JK, et al. DEVELOPMENT OF A NEW, MORE SENSITIVE IMMUNOASSAY FOR 
HUMAN TRYPTASE - USE IN SYSTEMIC-ANAPHYLAXIS. Journal of Clinical Immunology. 1994;14(3):190-204.

6. Scientific T. http://www.phadia.com/en/Products/Allergy-testingproducts/ImmunoCAP-Lab-Tests/ImmunoCAP-Tryptase/ Sweden2015 [

7. Komarow HD, Hu Z, Brittain E, Uzzaman A, Gaskins D, Metcalfe DD. Serum tryptase levels in atopic and nonatopic children. Journal of Allergy and Clinical Immunology. 2009;124(4):845-8.

8. Belhocine W, Ibrahim Z, Grandne V, Buffat C, Robert P, Gras D, et al. Total serum tryptase levels are higher in young infants. Pediatric Allergy and Immunology. 2011;22(6):600-7.

9. Ibrahim Z, Bongrand P, Carayon P, Vitte J. Determination of the baseline tryptase level in a pediatric population. Revue Francaise D Allergologie. 2009;49(7):524-7.

10. De Schryver S, Halbrich M, Clarke A, La Vieille S, Eisman H, Reza Alizadehfar, MDa, Lawrence Joseph, PhDf, Judy Morris, MD, MScg, Moshe BenShoshan, MD, MSca,. Tryptase levels in children presenting with anaphylaxis: Temporal trends and associated factors. J Allergy Clin Immunol. 2015.

11. Brown SGA, Stone SF, Fatovich DM, Burrows SA, Holdgate A, Celenza A, et al. Anaphylaxis: Clinical patterns, mediator release, and severity. Journal of Allergy and Clinical Immunology. 2013;132(5):1141-+.

12. NICE guideline ANAPHYALXIS.

13. Yunginger JW, Nelson DR, Squillace DL, Jones RT, Holley KE, Hyma BA, et al. LABORATORY INVESTIGATION OF DEATHS DUE TO ANAPHYLAXIS. Journal of Forensic Sciences. 1991;36(3):857-65.

14. Mayer DE, Krauskopf A, Hemmer W, Moritz K, Jarisch R, Reiter C.

Usefulness of post mortem determination of serum tryptase, histamine and diamine oxidase in the diagnosis of fatal anaphylaxis. Forensic Science International. 2011;212(1-3):96-101.

15. Edston E, Eriksson O, van Hage M. Mast cell tryptase in postmortem serum reference values and confounders. International Journal of Legal Medicine. 2007;121(4):275-80.

16. McLean-Tooke A, Goulding M, Bundell C, White J, Hollingsworth P. Postmortem serum tryptase levels in anaphylactic and non-anaphylactic deaths. Journal of Clinical Pathology. 2014;67(2):134-8.

17. Yavuz ST, Sackesen C, Sahiner UM, Buyuktiryaki B, Yilmaz EA, Sekerel BE, et al. Importance of serum basal tryptase levels in children with insect venom allergy. Allergy. 2013;68(3):386-91.

18. Sahiner UM, Yavuz ST, Buyuktiryaki B, Cavkaytar O, Yilmaz EA, Tuncer A, et al. Serum basal tryptase may be a good marker for predicting the risk of anaphylaxis in children with food allergy. Allergy. 2014;69(2):265-8.

19. Johnson MR, Verstovsek S, Jorgensen JL, Manshouri T, Luthra R, Jones DM, et al. Utility of the World Health Organization classification criteria for the diagnosis of systemic mastocytosis in bone marrow. Modern Pathology. 2009;22(1):50-7.

20. Sperr WR, El-Samahi A, Kundi M, Girschikofsky M, Winkler S, Lutz D, et al. Elevated tryptase levels selectively cluster in myeloid neoplasms: a novel diagnostic approach and screen marker in clinical haematology. European Journal of Clinical Investigation. 2009;39(10):914-23. 